\title{
Resignificación de cuerpos olvidados: Análisis del montaje Los que van quedando en el camino dirigido por Guillermo Calderón (2010)
}

\author{
Javiera Larraín George \\ Pontificia Universidad Católica de Chile - CONICYT \\ javiera.larraing@gmail.com \\ Artículo bajo licencia Creative Commons \\ Atribución 4.0 Internacional (CC BY 4.0) \\ ENVIADO: 2019-05-09 \\ ACEPTADO: 2019-06-07
}

\section{RESUMEN}

En 2010, en conmemoración del bicentenario de la independencia de Chile, el director Guillermo Calderón decidió aceptar la oferta del Festival Internacional Santiago a Mil para dirigir la obra Los que van quedando en el camino, escrita por Isidora Aguirre, y originalmente estrenada en 1969. Este trabajo pretende analizar críticamente la relectura de Calderón; quien no solo decide dirigir la obra, sino que también quiere mostrar el estado de vigencia de la misma en el Chile del 2010. Para ello, decide invitar a una parte del elenco original que participó en la obra de 1969 y utiliza como escenario uno de los salones del antiguo Congreso Nacional; en un intento por fracturar la memoria a través de la presencia material de aquellos cuerpos marcados por el paso del tiempo y que pareciera la Historia oficial busca dejar atrás. sitio.

\section{RESUMO}

Em 2010, na comemoração do bicentenário da independência do Chile, o diretor Guillermo Calderón decidiu aceitar a oferta do Festival Internacional de Santiago a Mil para dirigir a obra Los que van quedando en el camino, escrita por Isidora Aguirre e originalmente lançada em 1969. Este trabalho visa analisar criticamente a releitura de Calderón, que não só decide dirigir o trabalho mas também quer mostrar o estado de sua validade no Chile de 2010. Para isso, ele decide convidar uma parte do elenco original que participou da obra de 1969 e usou como palco um dos espaços do antigo Congresso Nacional na tentativa de fraturar a memória através da presença material desses corpos marcados pela passagem do tempo e que parecia que a história oficial procura deixar para trás.

KEYWORDS

Memória, corpo, história, afetos, teatro de site.

\section{ABSTRAC}

In 2010, in commemoration of the bicentennial of the independence of Chile, the director Guillermo Calderón decided to accept the offer of the International Festival Santiago a Mil to direct the play Los que van quedando en el camino, written by Isidora Aguirre, and originally released in 1969. This paper aims to critically analyze the re-reading of Calderón; who not only decides to direct the work, but also wants to show the current status of it in the Chile of 2010. To do this, he decided to invite a part of the original cast that participated in the play of 1969 , and used as a stage one of the halls of the old National Congress; in an attempt to fracture the memory through the material presence of those bodies marked by the passage of time and that it seems the official History seeks to leave behind.

KEYWORDS

Memory, body, History, affects, site-specific theatre. 
DOMINGA. Hermana, nombre a Juan Leiva, que dio su vida por los campesinos.

PEDRO. Él nos trajo la verdad...

JOSÉ. Y la rebeldía, con sus palabras...

DOMINGA. La palabra de Juan Leiva era como un pan blanco y limpio... Junto a la galleta sucia que le daban al peón campesino. Isidora Aguirre, Los que van quedando en el camino (1969)

La obra del dramaturgo y director teatral Guillermo Calderón (48) ${ }^{1}$ es basta y prolífica, ya no solo en Chile; sino en todo el extranjero. Ha sido invitado para escribir y dirigir en prestigiosos teatros dentro del mundo: Düsseldorfer Schauspielhaus, Theater Basel, HAU Hebbel am Ufer, el Royal Court Theatre, Center Theatre Group, y el Public Theatre en la ciudad de Nueva York, donde también dirigió Neva con actores norteamericanos (The Public, Nueva York [2012]), al igual que Villa (Play Co, Nueva York [2017]). Las obras de Calderón han recorrido extensamente el mundo, destacando: Uruguay, Brasil, Bolivia, Canadá, Portugal, México, Cuba, Colombia, Escocia, Grecia, Estados Unidos, Francia, Italia, Inglaterra y, por supuesto, Chile. Participando -asimismo- en importantes festivales: Festival Internacional de Teatro de Buenos Aires (FIBA), Festival Fringe de Edimburgo, Festival de Artes Escénicas de Seúl, Festival Chekhov en Moscú, Festival de Teatro Iberoamericano en España, TeatroStageFest, Festival de Teatro de Viena, Festival Mundial de Teatro en Bruselas, Festival Bajo el Radar del Teatro Público, entre otros.

La crítica nacional ha señalado -casi por unanimidad- que Calderón es uno de los autores más importantes de las últimas décadas dentro de nuestra escena nacional (Labra, Ibacache, Bahamondes, Letelier, Oyarzún, Lagos) y la prensa internacional ha alabado sus puestas en escena en el extranjero (The Guardian, The New Yorker, The Washington Post, El País, Clarín). De la misma forma, en el mundo académico es posible encontrar no poco-aunque tampoco bastante- material de estudio en torno a su trabajo; sobre todo artículos y tesis de pregrado y postgrado en relación a algunas de sus obras. La mayoría de estas revisiones - sean prensa, crítica especializada o estudios académicos- destacan el papel predominante de la palabra dentro de la construcción de sus piezas, que según Juan Andrés Piña (2015), en Calderón: “la envolvente o incluso apabullante marea verbal alcanza por momentos una cima poética; en otros casos primará la fuerza ideológica de quien expone un argumento, su capacidad de representación de un desgarro íntimo, el soliloquio de alguien extraviado en el dolor y la soledad o, también, el relato de una historia que un personaje narra a los demás" (170-171). Por su parte, Carola Oyarzún (2010) enfatiza que: "Calderón se instala en nuestro campo teatral como una de las figuras más destacadas. Su dedicada relectura de textos clásicos, sumada a su constante preocupación por las coyunturas históricas pasadas (guerras, revoluciones y revueltas callejeras) y presentes hablan, sin duda, de una dramaturgia/dirección que cuestiona el sentido del teatro en contextos dominados por la cri-

$1 \quad$ Nacido en Santiago, en 1971, su juventud se encuentra marcada por los últimos años de Dictadura en Chile. Estudia Teatro en la Universidad de Chile (19891993). Con posterioridad realiza estudios de especialización en el extranjero: primero, en el Actor's Studio, en Nueva York, EE.UU., que no continuó por no sentirse tan a gusto con las lógicas de actuación stanislavskianas; lo cual lo llevaría a profundizar, en segunda instancia, en el teatro físico en la Scuola Dell'Arte en California, EE.UU., y en la Scuola Internazionale dell'Attore Comico, en Italia. Además, cursó un Master en Artes Liberales con mención en Cine en la City University of New York, EE.UU. 
sis" (305). Mientras que, María de la Luz Hurtado (2008) señala que lo metateatral cruza su obra y: "se constituye en la indagación en torno a las claves [...] de la memoria emotiva y física de los actores: de su vida personal, de lo vivido, sentido, observado, experimentado en carne propia, como fuente y correlato de la construcción de un personaje «real», «creíble», «vivo», afectiva, social e históricamente fundado" (45).

Para el propio autor, sus piezas -que siempre han tenido un marcado interés político- han ido declarando de manera más explícita sus filiaciones y declaraciones políticas; como bien podemos ver desde Villa + Discurso (2010), Escuela (2013) y - por sobre todo- Mateluna (2016) y Dragón (2019). En efecto, consultado sobre la condición política de su trabajo, el director teatral manifiesta:

El rol de mi teatro es poner en el escenario preguntas que me han acompañado durante todo este tiempo, que tienen que ver principalmente con la historia política de mi país. Yo crecí en dictadura, seguí creciendo en democracia y ese trauma de crecer en ese contexto todavía me sigue motivando para seguir escribiendo. El teatro es un excelente lugar para seguir explorando ese tipo de historias, que no son sólo mías, sino que son compartidas por una generación entera (en Moffat, 2011).

\section{Y agrega, en este mismo sentido:}

Siempre he sido una persona muy interesada en la política, en la historia. Ocurre que con el tiempo uno va coleccionando opiniones acerca de la vida, acerca del país y esas opiniones se acumulan. Cuando escribo una obra, parto de esas ideas. Otros dramaturgos parten de personajes o de un mundo estético. Yo parto de ideas concretas que tienen que ver con una visión política (González, 2013: 12).

Dicho interés sobre la historia socio-política de Chile, motivaría a Calderón a aceptar el ofrecimiento del Festival Internacional Santiago a Mil para remontar en el 2010 -en el marco de las celebraciones por el Bicentenario de la independencia de Chile - la obra Los que van quedando en el camino de Isidora Aguirre, estrenada originalmente en 1969 bajo la dirección de Eugenio Guzmán, y con veintiún actores en el elenco pertenecientes al Teatro Experimental de la Universidad de Chile. En su época, la obra alcanzó un gran revuelo en la prensa y en la crítica, por dos factores determinantes. El primero de ellos, se teje en el orden de la fábula; pues esta, buscaba recrear la matanza de los campesinos alzados en Ránquil en $1934^{2}$, en un claro alcance con los problemas sociales que enfrentaban los campesinos en la década de los 60 -en donde la obra se estrenara por primera vez- con la llamada 'Reforma Agraria de Macetero' del Gobierno de Alessandri3. Mientras que el segundo hecho que llamó la atención, fue la construcción del texto dramático

2 La Masacre o Levantamento de Ránquil ocurrió en junio y julio de 1934, cuando grupos de campesinos y mapuche de la antigua provincia de Malleco, en Chile, se sublevaron en contra de los abusos de los patrones -avalados por las reformas agrarias del Gobierno- provocando una revuelta de proporciones insospechadas; que se estima en más de un centenar de muertos, aunque otros antecedentes los elevan a más de trescientos.

En 1962, Alessandri promulga la ley 15.020 que establecía un conjun( la ley preexistente, sino fortalecer el mantenimiento del orden social existente. De esta forma, es posible apreciar que - para Alessandri y el Oficialismo- la posibilidad de desarrollar un proceso de modernización en el campo chileno quedaba supeditada a la mantención de las estructuras sociales y políticas de carácter latifundista que determinaban la agricultura nacional desde la época republicana; y de ahí que la reforma reciba el nombre -o mote- de 'macetero'. escrito por Aguirre -con claros elementos pertenecientes al teatro épico brechtiano - que se componía como una revelación episódica; en donde, los únicos sobrevivientes de la tragedia (Mamá Lorenza y Juanucho) recordaban la historia de los muertos, como una forma de rescatarlos del olvido de la memoria oficialista del Estado.

Calderón no solo decide remontar la obra, sino que quiere mostrar la actualidad de la misma en el Chile del 2010, cuarenta años después que viera la luz por vez primera. Para ello, decide invitar a parte del elenco original ${ }^{4}$ que participó en el montaje de 1969; y dispone como locación, de uno de los salones del Ex-Congreso Nacional, ubicado en pleno centro de Santiago, antes de su cierre y traslado a Valparaíso. Así, este imponente edificio neoclásico, concebido por el arquitecto francés Claude Francoise Brunet, y que albergara la sede del Congreso Nacional entre 1876 y 1973; se transforma en un escenario improvisado para un espectáculo teatral, casi en un gesto cómico por parte de la dirección, como si Calderón quisiera recordarnos que esta 'sala poco convencional' ya fue -con anterioridad- escenario de tragedias fundamentales que marcaron la historia chilena, como lo fuera -la propia-matanza de Ránquil.
4 En la puesta en escena de 2010, participaron: Mónica Carrasco, Diana Sanz, Mario Montilles, Sergio Madrid, Mario Lorca, César Arredondo, Gabriela Medina, Violeta Vidaurre, Pedro Villagra, Sonia Mena, Víctor Rojas, Regildo Castro, Hernán Vallejo, Ramón Sabat, Eugenio Morales y Sergio Hernández. Varios de ellos - por desgracia-actualmente fallecidos. 


\section{LA CARGA SIMBÓLICA DEL ESPACIO ARQUITECTÓNICO: PRIMERAS APROXIMACIONES AL TEATRO DE SITIO}

La utilización del Ex-Congreso como locación del remontaje de Calderón, se inscribe como una práctica del denominado site-specific theatre; en el cual -en esta oportunidad- el director dará sus primeros pasos, que después profundizará en su siguiente obra (Villa + Discurso). Nick Kaye (2000), considera -en relación a la definición propia del término-que:

Site-specific, can be understood in terms of this process, while a 'site-specific work' might articulate and define itself through properties, qualities or meanings produced in specific relationships between an 'object' or 'event' and a position it occupies. After the 'substantive' notion of site, such site-specific work might even assert a 'proper' relationship with its location, claiming an 'original and fixed position' associated with what it is (1) 5 .

A su vez, Patrice Pavise (2011) define el 'teatro de sitio' como una:

Puesta en escena y espectáculo concebidas a partir y en función de un lugar encontrado en la realidad (y, por tanto, fuera de los teatros establecidos). Una gran parte del trabajo reside en la búsqueda de un lugar, a menudo insólito, cargado de historia o impregnado de una atmósfera potente: hangar, fábrica abandonada, barro de una ciudad, casa o piso. La inserción de un texto, clásico o moderno, en este lugar hallado le confiere una nueva luz, una fuerza insospechada e instala al público en otra relación frente al texto, al lugar y al propósito. Este nuevo marco proporciona una nueva situación de enunciación que, como en el land art, nos hace redescubrir la naturaleza y la disposición del territorio y da al espectáculo un entorno insólito que constituye todo su encanto y toda su fuerza (453).

Esta última definición guarda una estrecha relación con las obras convencionales de teatro -aquellas que ocurren en una sala negra de caja italiana-, considerando que la performance se cifra tanto en los intérpretes como en el lugar mismo. Mientras que, la aproximación brindada por Kaye se resiste a distinguir las características comunes dentro de un género en disputa y se centra en los procesos que involucran a los objetos y a los eventos; y-por sobre todo- en el lugar que estos ocupan. Pese a los distintos alcances, es claro que una performance en torno al site-specific: "involves an activity, an audience and a place, then creative opportunities reside in the multiple creative articulations of $u s$, them and there" (Pearson, 2010: 19) ${ }^{6}$. Por consecuencia, este tipo de teatro conlleva un compromiso experiencial y fenomenológico con el espectador, tal cual señala Calderón: "[hacerlo ahí] era como una paradoja y era como un cierre del círculo de la historia. Era muy importante, hacerse cargo de eso. Yo no quería hacer una obra estrictamente cerebral, yo quería hacer una obra que restaurara la emoción política de

\footnotetext{
5 [Trad.]: "El sitio específico se puede entender en términos de este proceso de [ubicación], mientras que un 'trabajo específico del sitio' podría arti cularse y definirse a sí mismo a través de propiedades, cualidades o significados producidos en relaciones específicas entre un 'objeto' o 'evento' y la posición que ocupan. Después de la noción 'sustancial' del sitio, tal trabajo específico de sitio podría incluso afirmar una relación 'adecuada' con su ubicación, reclamando una 'posición original y fija’ asociada con lo que es”.
}

6 [Trad.]: "involucra una actividad, una audiencia y un lugar, luego las oportunidades creativas residen en las múltiples articulaciones creativas de nosotros, ellos y alli". la época. Porque eso era lo importante, porque la política es emoción, y la emoción es política” (en Jeftanovic, 2015: 95-96). Así, parte del énfasis del montaje se sitúa en el contacto del público con el lugar y su carga histórica; pues Calderón apunta también hacia las emociones encontradas que representa el Ex-Congreso como lugar de memoria ${ }^{7}$, ya que la democracia nunca logró reconstituirse allí luego que Pinochet cerrara el parlamento y lo trasladara a un nuevo edificio mandado a construir por él en Valparaíso, edificio donde aún operan los parlamentarios hasta la fecha.

Pero, el espacio no solo es utilizado en términos significantes por su carga simbólica dentro de la historia chilena; también como una sala de teatro propiamente tal que albergará a cientos de espectadores. María de la Luz Hurtado (2015) precisa que: "Los primeros espectadores en entrar se abalanzan a los asientos otrora destinados a los congresistas y los demás se van ubicando en los balcones y graderías diseñadas para la escucha y presión ciudadana durante la discusión de las leyes" (10). Calderón interviene la materialidad canónica del Ex-Congreso; dispone de fardos de paja al centro del hemiciclo para que los actores se sienten, y distribuye al público como si estos fueran los parlamentarios que antes allí albergó la Cámara. Jen Harvie (2005) indica -en este mismo sentido- el potencial del site-specific theatre para explorar espacial y materialmente la Historia y mediar el complejo campo de identidades que esta produce: "Site-specific performance may appropriate a pre-existing spatial configuration, annexing the architectural features of site to distribute its audience -staircases, balconies or the terraces of a sales ring, providing prospects unfamiliar or impossible to conspire in the auditorium" $(42)^{8}$. En este caso, el director buscaría apropiarse del devenir de la Historia nacional, utilizando como escenario el lugar en que -en el plano de la realidad-se ocultó, y en parte respaldó. la matanza de Ránquil: el antiguo Congreso Nacional.

Asimismo - al final de la obra- Calderón propone un desenlace escénicamente distinto al original. Los actores marchando, cantan el himno de Advis/Castro (sin la perfecta entonación vocal que primara en la versión de 1969, dado el desgaste natural de sus voces). Mientras que -en paralelo- se escucha una grabación en off, vítores a los campesino de Ránquil; y desde los balcones se despliegan dos grandes pancartas - donde se lee ‘Los días buenos' y 'Los días malos'- y se arrojan panfletos que caen con estrépito sobre el público; en una clara referencia a los años de movimiento social de la Unidad Popular en los 60, y que llevarían a Allende al poder. El director, busca resignificar historiográficamente esta obra, puesto que: "Calderón fortalece la dimensión metateatral con este recurso que designa a la dramaturgia de Aguirre como panfleto, a los días buenos como los de la vigencia artístico/política de dramaturgos y actores de esa generación de los '60, y a los días malos como los de su propia imposibilidad actual, tiempo vacío de acción y drama, de ausencia" (Hurtado, 2015: 26). Aquí, el ejercicio de 'teatro de sitio' no es -en lo absoluto- meramente estético; sino que

$7 \quad$ La primera sesión de la Cámara de Diputados que abordó la evaluación de las noticias que llegaban de la zona de Ránquil en la época, tuvo lugar el 10 de julio de 1934. El documento oficial de dicha sesión da cuenta no solo del desconocimiento absoluto de los congresistas con las características de la zona en cuestión; sino que demuestra -también- un nulo interés de los parlamentarios en buscar confirmar los trágicos hechos ocurridos, pues ninguna comitiva fue enviada al lugar para confirmar la veracidad de la información que llegaba a la capital.

8 [Trad.]: “La performance de site-specific puede apropiarse de una configuración espacial preexistente, anexando las características arquitectónicas del sitio para distribuir su audiencia: escaleras, balcones de las terrazas, proporcionan perspectivas desconocidas o imposibles para conspirar en el auditorio". 
es una poderosa estrategia discursiva contra el olvido, como bien declara Pearson (2010): "Site-specific performance can be especially powerful as a vehicle for remembering and forming a community for at least two reasons. First, its location can work as a potent mnemonic trigger, helping to evoke specific past times related to the place and time of performace and faciliting a negotiation between the meaning of those times" (176) ${ }^{9}$. Por consiguiente, Calderón logra no solo recordar; sino -además(re)crear identidades generacionales que están significativamente determinadas por la materialidad del espacio en que se encuentran, en este caso el antiguo Congreso Nacional.

\section{LA CONSTRUCCIÓN ACTORAL DE 'LO REAL’ EN UN PLANO METATEATRAL ${ }^{10}$}

Para la dirección, la importancia de este trabajo radicaba en plasmar con realidad la naturaleza de la pieza, respetando sus propios principios directoriales; aquellos que se oponen a una actuación ampulosa o artificiosa. Este propósito fue, según relata el propio Calderón en entrevista con Andrea Jeftanovic, bastante difícil de ejecutar durante el proceso de ensayo, puesto que los actores tendían a declamar el texto o a imitar el habla campesina. Calderón buscaba una naturalidad vocal por parte de los intérpretes, que respetaran la prosodia del texto y que no sobreactuaran una emoción que solamente ya estaba mediada por la palabra dramatúrgica. A su vez, decidió no 'disfrazarlos' de campesinos, ya que era imposible que se vieran -desde la realidad de sus cuerpos- como agentes orgánicos del campesinado chileno:

Porque la ropa del campesino, por lo general, son ropas ajadas como viejas, que nunca funciona porque es siempre como una caricatura, y además es innecesaria. Porque uno como espectador tolera cierto nivel de eso. Entonces ves a una señora como Sonia Mena, vestida de mujer campesina, con ropa pobre, con sus manos perfectas y su manicure. La apuesta es que se puede ser mucho más campesino si uno trabaja con lo que el público pueda proyectar, en realidad son claves súper comunes del teatro contemporáneo. Entonces había que enfatizar el debate político y porque también debía hacerse cargo del lugar, vestirlos como si fueran parlamentarios, con ciertos toques, pero al mismo tiempo que se explicitara que estábamos en el mundo campesino, por eso la presencia de las sillas de paja y las ojotas (en Jeftanovic, 2015: 95).

Nuevamente, Calderón opta por la simpleza escenográfica. Unas simples ojotas y unos fardos de paja son suficientes para traer el imaginario del campesinado chileno frente a los espectadores. Además, el vestuario del elenco -ataviados todos con sobrios trajes formales de dos piezas- produce un contrapunto interesantísimo con estos otros dos elementos; puesto que el atuendo de oficinista se cuadra con la estética formal que el salón del hemiciclo representa, pero se yuxtapone a las ojotas y los fardos, procurando una sugestiva contradicción. Estas decisiones, fueron -en un principio- bastante polémicas para el elenco; quienes no entendían el sentido de 'no hablar como los campesinos' o 'vestirse como tal'. El elenco terminó por aceptar las indicaciones de Calderón de no trabajar desde un mimetis-

10 El teatro metateatral -desde una perspectiva clásica- ha sido entendido como un desdoblamiento de la ficción dramática en dos niveles: el primero y más aparente, es aquel que está ocupado de la pieza misma, con sus diégesis, sus personajes, sus didascalias; el segundo, es aquel que articula y organiza una ficción contando con la existencia del primer nivel y trata de desbordarlo o -mejor aún- explotarlos para ofrecer más posibilidades de que su mensaje llegue al espectador (Villarino, 2006: 909). Empero, la conceptualización del término en la que el presente artículo se inscribe, se encuentra más cercana a los postulados de Tobin Nellhaus (2010), quien considera que para entender o explicar la metateatralidad se requiere un análisis ontológico de la performance teatral y una examinación histórica de las conexiones entre cambios y estructuras sociales, y entre cambios y estructuras de las estrategias performativas. Para Nellhauss, la performance teatral -tal como ocurre en Los que van quedando en el camino de Calderón- hace mella de la estructura social ontológica; pues -al igual que estapuede ser entendida simultáneamente desde su condición material, sociológica y significativa; y circunscribirse por medio de las acciones de agentes individuales o agentes grupales, un performer -cuerpo avejentado y en resistencia del actor-o compañías escénicas correspondientemente -el elenco original del montaje de 69. Cada uno de estos agentes puede prodigar de una capacidad autorreflexiva; en la que el lenguaje es el sistema más obvio de signos, pero está lejos de ser el único. 
mo campesino, solo cuando el actor Mario Lorca les recordó que fue el propio Víctor Jara, quien -pese a sus ancestros campesinos- al dirigirlos en los 60, en el ITUC-DETUCH, les indicaba que no debían emular el habla campesina porque ellos eran -a final de cuentas- actores urbanos (Hurtado, 2015: 31).

La carga de 'lo real' se hace patente -consecuentementetanto en el espacio resignificado como en el cuerpo de los actores, que no busca ser 'adornado' o ‘maquillado'; Calderón precisamente se interesa en invitar a los actores del elenco original, pues ellos son la memoria viviente de aquel pasado olvidado que quiere representarse. Es más, varios de ellos también participaron del montaje de 1972, que no prosperó por el Golpe Militar al año siguiente. Por ello, la actuación se cifra desde la ontología de los cuerpos, 'lo real' está determinado por la corporeidad material del actor, quien -en este montaje- se vuelve más importante que el personaje que representa. A razón de esto, Hurtado (2015) señala que: “el espectador se convierte en testigo no solo de la derrota de los campesinos sino del fracaso de los intentos de los actores de construir la acción del texto de Aguirre, violentando la ética de esta generación de ser fieles y dotados intérpretes o servidores del texto del autor" (13). Para Calderón, este proceso de dirección -desde la actuación- fue fácil y difícil con este gran elenco; porque -por una parte- ellos podían pararse con un gran peso y propiedad sobre el escenario, pero - por otra- a veces caían repetidamente en 'formas interpretativas adquiridas con los años' que hubo que -en palabras del autor- 'ir desimplificando' (en Jeftanovic, 2015: 97). Pese a esto, los actores acogieron las indicaciones de Calderón y todos ellos - una vez terminada la temporada- le hicieron saber, al ver el video de la grabación de la obra, que lograron entender a la perfección aquello que él estaba buscando, que era -en resumidas cuentas- el 'borronear' pero sin hacer desaparecer la caricatura del personaje campesino, para hacer emerger y dar protagonismo a las propias figuras de ellos como actores.

Calderón plantea -por ende- un choque metateatral de dos estilos actorales distintos, que pueden verse en escena al unísono. Durante cada función, es posible ver a los intérpretes debatiéndose entre un primer impulso -natural- de respetar la propuesta original acorde a las instrucciones de la dupla Guzmán/Aguirre; y el seguimiento de la propuesta de su nuevo director. Hurtado (2015) rescata que:

Cabe aún preguntarse cómo construye Calderón sentido y metateatralidad desde este choque entre Stanislavski (activo en los actores) y la deriva contemporánea de Brecht (su propia propuesta direccional) al trabajar los repliegues de la triple memoria traumática 1934/1969/2010 en Los que van quedando en el camino. El director postula [...] una doble memoria deseada por estos actores era la del actor respecto a su oficio y, con ella, la de cumplir, junto a la dramaturga y al director, la función ancestral del artista de ser el animador de la memoria de su tribu. ¿Es esta memoria de la tribu, o memoria ciudadana, la de la matanza de Ránquil, las de la Dictadura, y/o la tragedia ontológica de lo humano? (20-21).

Frente a esta última pregunta, la respuesta es clara. Calderón condensa en la interpretación sujeta al cuerpo de estos viejos actores, diversas memorias que conviven al mismo tiempo. En términos de Hornby (1986), aquí se está en presencia de aquel tipo de metateatralidad que hace referencia a la literatura y a la vida real, y que puede obrar a través de la cita, la alegoría, la parodia y la adaptación; inscribiéndose la versión de Calderón desde el plano de la cita, puesto que sus decisiones directoriales citan y dialogan las que antes tomara Guzmán en 1969. En consecuencia, acorde a la propuesta metadiegética de Hornby, en el remontaje propuesto por Calderón: "when literary/scenic citation within the play moves toward literary/scenic criticism is also moves toward the play as self-reference. The audience cannot help but apply the same standards that are being propounded against the play itself" $(92)^{11}$. Es justamente, esta condición metateatral, la que atravesaría la presente propuesta - y toda la obra de Calderón- para construir una ontología escénica de los afectos -y efectos- en sus nexos con 'lo real'; en este caso sobre cuerpos que batallan por resistir.
11

[Trad.]: "cuando la cita literaria/escénica dentro de la obra se mueve hacia la crítica literaria/escénica también se mueve hacia la obra como autorreferencia. La audiencia no puede evitar aplicar los mismos estándares que se proponen contra la obra en sí” 


\section{DE AFECTOS Y CUERPOS CON MEMORIA... QUE VAN QUEDANDO EN EL CAMINO}

En la versión del 2010 de Los que van quedando en el camino se evidencia el trauma de la pérdida de 'Los buenos días'; pero estos no se refieren al movimiento campesino del 30 , sino a los tiempos de la Unidad Popular. La derrota de los campesinos de Ránquil se presenta desde múltiples frentes; y son los espectadores quienes terminan de cerrar el acto significante con la determinada batalla que quieren considerar perdida ${ }^{12}$. Sobre escena vemos cuerpos viejos que se resisten y luchan por las casi dos horas que dura el espectáculo; se resisten al paso de los años, al olvido y al cansancio. A este respecto, según Peggy Phelan (1997): "The enactment of invocation and disappearance undertaken by perfomance and theatre is precisely the drama of corporeality itself. At once a consolidated fleshy form and an eroding, decomposing formlessness, the body beckons us and resists our attempts to remake it" $(4)^{13}$. Los cuerpos de los intérpretes se debaten constantemente entre la presencia y la ausencia, en un flujo entre 'el aquí y el ahora'; volviéndose referentes semióticos o-como arguye Fischer-Lichte (2014)- corporalidades fenoménicas.

Pero esta resistencia, no es fortuita ni exagerada; y no está solo determinada por la edad de los intérpretes (varios cercanos a los ochenta años), sino también por sus limitaciones físicas propias de su edad, como Calderón cuenta:

Mario Montilles me dijo 'la memoria me falla' y Sergio Madrid me dijo 'el tanque lo podríamos tapar', pero yo dije 'no, el público crea la ficción, ustedes no tienen porque mentir', yo pensaba es mejor evidenciarlo y aceptaron. Al principio no entendieron mucho, a Mario le daba vergüenza, pero no se iba a aprender el texto, si ni siquiera se aprendía lo que tenía que hablar, por eso le poníamos un apuntador donde hablaba y soplaba. El público entiende perfectamente lo que es el teatro, entiende que es una ficción, acepta todo eso, es parte de la historia de la obra. Yo quería que los actores se vieran dignos, que no se vieran tratando de ser jóvenes, quería que se vieran sus cuerpos viejos, sus problemas de memoria, que todo eso fuera parte de la obra (en Jeftanovic, 2015: 97).

Durante todo el montaje vemos a los actores resistirse al cansancio físico, haciendo una muestra incólume de su oficio; pese a las respiraciones entrecortadas por el agotamiento, a la debilidad muscular, o a los lentos desplazamientos. De hecho, Montilles personifica a Juanucho -el niño- que le pide a su mama Lorenza que le cuenta la historia de sus padres, ambos asesinados en la matanza de Ránquil. Su batalla es contra el olvido, contra ser olvidado; tal como Aguirre luchaba para que la Historia de las matanzas de los campesinos - del 34 y del 69- no fueran ol-

12 Es interesante rescatar el hecho que, una de las funciones de Los que van quedando en el camino tuvo que ser suspendida por la Segunda Vuelta Electoral Presidencial del año 2010, en donde ganaría Sebastián Piñera (candidato de la coalición conservadora de Derecha) para su primera Presidencia. La función posterior a este hecho, cobró un especial significado; sobre todo cuando -al inicio de la obra- los campesinos responden que nada ha cambiado para ellos en la actualidad, que 'todo sigue igual' y que se repiten las mismas injusticias.

[Trad.]: “La promulgación de la invocación y la desaparición llevada a cabo por la performance y el teatro es precisamente el drama de la corporeidad misma. A la vez, una forma carnosa consolidada y una amorfa descompuesta que se erosiona, el cuerpo nos llama y resiste nuestros intentos de rehacerlo"

[Trad.]: “La promulgación de la invocación y la desaparición llevada a cabo por la performance y el teatro es precisamente el drama de la corporeidad misma. A la vez, una forma carnosa consolidada y una amorfa descompuesta que se erosiona, el cuerpo nos llama y resiste nuestros intentos de rehacerlo" vidadas ni enterradas por el Oficialismo, puesto que exiguos son los libros de Historia que mencionan estos hechos. Lo importante -en razón a lo ya dicho- no es si Montilles no podía recodar sus textos; lo vital era verlo a él-con sus problemas de memoria a cuestas- leer en escena sus parlamentos, siempre asistido por una persona para poder desplazarse, siempre indicándole sus textos y ayudado por microfonía. Es, en ese momento, en donde el cuerpo enseña las huellas de su memoria, aunque irónicamente esto suceda en la incapacidad de recordar.

Pese a que en un comienzo se dé cuenta que la Historia no ha avanzado en lo absoluto, cuando los actores corean que aquellas cosas que ocurrieron en el pasado son 'igual que hoy'. Aquel 'hoy' se contrapone con los cuerpos gastados de los intérpretes, que sí han cambiado -y bastante. Así, para Gutiérrez (2012): “La pieza de Calderón ofrece una mirada múltiple, fragmenta la experiencia presente para hacerse cargo de muchas temporalidades [...], sincretismo agotador y a veces desolado" (261). El pasado -por tanto- se vuelve presente en la performance de estos cuerpos maltrechos y solo a través de ellos puede ser aprehendido, como menciona Rebecca Schneider (2011): "If the past is never over, or never completed, 'remains' might be understood not solely as object or document material, but also as the immaterial labor of bodies engaged in and with that incomplete past: bodies striking poses, making gestures, voicing calls, reading words, singing songs, or standing witness" (33) ${ }^{14}$. Si alguna vez ha existido un espacio real entre la memoria y la Historia, este se encuentra en la transitoriedad y porosidad de los cuerpos: "The resiliently irruptive rub and call of live bodies [...] insist that physical acts are a means for knowing, bodies are sites for transmission even if, simultaneously, they are also manipulants of error and forgetting" (38) ${ }^{15}$. Es en las huellas visibles del cuerpo, donde se consigna y puede leerse la Historia; y es, en la resignificación de estos cuerpos olvidados que puede re-escribirse la misma, como logra la propuesta de dirección de Calderón.

Los cuerpos de Mario Montilles, Diana Sanz, Sergio Madrid, Mario Lorca, y los demás actores del elenco se construyen como corporalidades fenoménicas, que la dirección intenta poner en contra de la memoria del olvido. En el montaje, para Calderón: "Su idea es concederle al cuerpo una posición de prevalencia paradigmática equivalente a la que tiene el texto, en lugar de subsumirlo al paradigma textual" (Fischer-Lichte, 2014: 184). Los cuerpos del elenco original generan una textualidad interna, que no solo pretende: "desviar la atención una y otra vez hacia el cuerpo fenoménico del actor, sino fijarlo en él, [así] la dramaturgia le brinda la oportunidad a la percepción de saltar al personaje de vez en cuando, con mayor o menor frecuencia dependiendo de la situación y de la realización escénica" (181). Es, a través del desgaste de estos cuerpos, que Calderón logra un doble ejercicio en el espectador: en el plano del raciocinio y en la dimensión de los afectos. Sus cuerpos gastados naturalmente por el paso del tiempo encarnan las subjetividades de la Historia, aquella emocionalidad que traspasa las cargas simbólicas del edificio institucional en donde se encuentran, y que pliega de cargas afectivas al espectador.

14 Trad.]: "Si el pasado nunca termina, o nunca se completa, los 'restos" podría entenderse no solo como material de objetos o documentos, sino también como el trabajo inmaterial de cuerpos comprometidos en y con ese pasado incompleto: cuerpos en poses de huelga, haciendo gestos, expresando llamadas, leyendo palabras, cantando canciones, o testificando de pie"

15 [Trad.]: "El roce y el llamado elásticamente disruptivo de los cuerpos vivos [...] insisten en que los actos físicos son un medio para conocer, los cuerpos son sitios de transmisión aunque, simultáneamente, también sean manipuladores del error y el olvido" 
Fischer-Lichte, E. (2014). Estética de lo performativo. Madrid: Abada Editores.

Harvie, J. (2005). Staging the UK. Manchester: Manchester University Press.

Hornby, R. (1986). Drama, metadrama and perception. London: Bucknell University Press.

Hurtado, M. de la. (2015). Imponiendo derrotas a triunfos del pasado: Corporizaciones de la memoria y el olvido en Los que van quedando en el camino de Guillermo Calderón 2010. Latin American Theatre Review 48 (2): 7-33.

González, D. (2013). Guillermo Calderón, el dramaturgo de la memoria. Revista PAT (56): 10-13. Recuperado de: http://www.revistapat.cl/numeros/PAT56/

Gutiérrez, P. (2012). Nota sobre Los que van quedando en el camino de Isidora Aguirre y su montaje del 2010. Anales de Literatura Chilena (17): 257-268.

Jeftanovic, A. (2015). La emoción política en Los que van quedando en el camino de Isidora Aguirre, dirigida por Guillermo Calderón para Santiago a Mil 2010. Entrevista a Guillermo Calderón. En: Jeftanovic, A.; Gutiérrez, P. (eds.). Archivo Isidora Aguirre. Composición de una memoria. Santiago: Ediciones El Clan, 92-99.

Kaye, N. (2000). Site-specific Art. Performance, place and documentation. London: Routledge.

Nellhaus, T. (2010). Theatre, communicatin, critical realism. New York: Palgrave MacMillan.

Moffat, A.; Torres, J. (2011, 23 de julio). Neva, de Guillermo Calderón, video de Escuela de Espectadores. Recuperado de: https://www.youtube.com/watch?v=FNM_AKZcQno

Pavise, P. (2011). Teatro en función de escenarios reales. En: Diccionario del teatro. Dramaturgia, estética, semiología. Buenos Aires: Paidós, 453.

Pearson, M. (2010). Site-Specific Performance. London: Palgrave Macmillan.

Phelan, P. (1997). Mourning Sex: Performing Public Memories. London: Routledge.

Schneider, R. (2011). Performing remains. Art and war in times of theatrical reenactment. New York: Routledge.

Villarino, M. (2006). La metateatralidad en entremeses de Cervantes y su escritura. En: Actas Plenarias Congreso "El Quijote en Buenos Aires". Madrid: Centro Virtual Cervantes, 909-914. 
